Goldschmidt 2021 Abstract

https://doi.org/10.7185/gold2021.6294

\section{Hf isotopic evidence for the gradual onset of Earth's mobile-lid tectonic regime}

ANN BAUER ${ }^{1}$, JESSE R REIMINK ${ }^{2}$, THOMAS CHACKO ${ }^{3}$, BRADFORD FOLEY ${ }^{2}$, STEVEN B. SHIREY ${ }^{4}$ AND D. GRAHAM PEARSON ${ }^{3}$

${ }^{1}$ University of Wisconsin-Madison

${ }^{2}$ Pennsylvania State University

${ }^{3}$ University of Alberta

${ }^{4}$ Carnegie Institution for Science

Presenting Author: annie.bauer@wisc.edu

Constraining the timing and mechanism of early continental crust growth on Earth is critical for the geosciences as continents exert a first-order control on many Earth processes. We have compiled and evaluated the lutetium-hafnium isotope compositions of globally distributed detrital zircons $>3.2 \mathrm{Ga}$ [1]. Different trends are revealed by the Hf isotope data (Fig. 1) for zircons older than $\sim 3.8$ Ga relative to those younger than $\sim 3.6$ $\mathrm{Ga}$, characterized by a shift from unradiogenic Hf isotope compositions, consistent with a long-extant Hadean source to the input of relatively juvenile $\mathrm{Hf}$ isotope compositions across this interval. Zircon and co-existing whole rock geochemical signatures recovered from well-characterized, meta-igneous rocks of the 4.02 to $2.9 \mathrm{Ga}$ Acasta Gneiss Complex of northern Canada exemplify trends in the global detrital zircon dataset, defining an interpretive template. The global zircon $\mathrm{Hf}$ isotope data record a transition from an early stagnant-lid tectonic regime, in which continental crust was formed by repeated remelting of ancient mafic crust that, unlike in the present-day, persisted at the surface for long periods of time, to the widespread inception of mobile-lid tectonics and associated crust production processes $\sim 3.8-3.6 \mathrm{Ga}$, with some regions transitioning before others.

[1] Bauer, A. M., Reimink, J. R., Chacko, T., Foley, B. J., Shirey, S.B., Pearson, D.G. (2020) Hafnium isotopes in zircons document the gradual onset of mobile-lid tectonics. Geochemical Perspectives Letters 14: doi:10.7185/geochemlet.2015.

Fig.1 Initial epsilon Hf binned in 50-Myr intervals from 4.25 to $3.25 \mathrm{Ga}$ for the compilation of detrital and igneous zircons [1]. The labels at right indicate the change-point analysis shift in each terrane, which occur heterogeneously between $\sim 3.8$ and $3.6 \mathrm{Ga}$, documenting a change from reworking of Hadean-aged material to input of more juvenile (more radiogenic Hf) magmas.

\section{Figure 1}

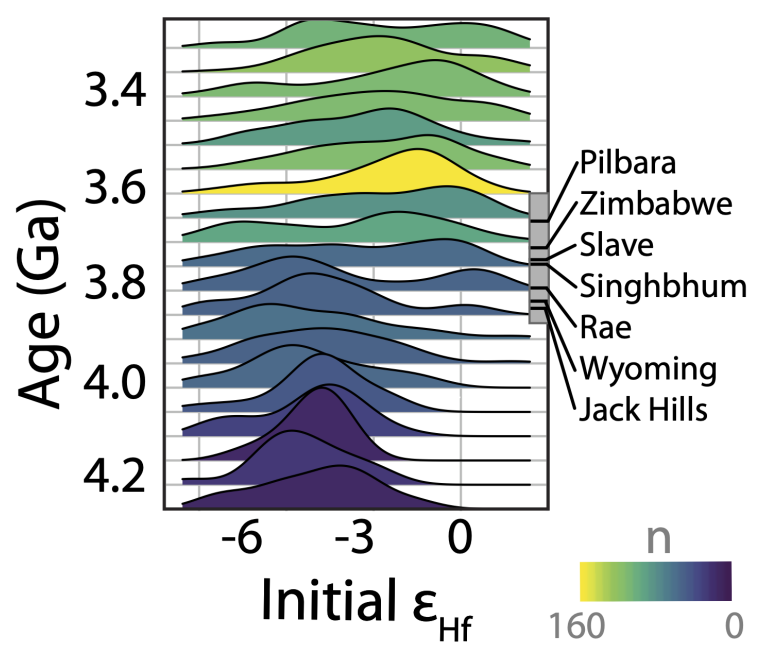

